\title{
WHO JOINS AND WHO FIGHTS? EXPLAINING TACIT COALITION BEHAVIOR AMONG CIVIL WAR ACTORS
}

\author{
MARTIN C. STEINWAND AND NILS W. METTERNICH
}

\begin{abstract}
Which armed organizations form coalitions despite the inherent difficulties of cooperation in civil wars? We introduce the concept of tacit coalitions, which pertains to strategic and informal coalition behavior between civil war actors to address this puzzle. Our theoretical model of coalition behavior takes in theater-wide conflict behavior to allow for predictions which coalitions are more likely to form. It provides novel insights to the way military synergies within potential coalitions affect the trade-off between pooling resources and worrying about the division of gains. The empirical section finds considerable support for our theoretical argument that actors are more likely to engage in tacit coalition behavior if a) potential coalitions are power balanced, and b) joint capability of potential coalitions is not too high, and c) when coalitions can unlock synergies. In addition it produces evidence for the important role of geography and ethnic ties in generating military synergies.
\end{abstract}

\section{INTRODUCTION}

In recent years, scholars of civil war have paid increasing attention to the dynamics of multiactor conflict. This research agenda has produced important insights about factors that facilitate cooperation (such as the pooling of military resources; Akcinaroglu, 2012; Bapat and Bond, 2012) and has identified a range of important mechanisms that decrease coalition coherence (e.g. outbidding, Cunningham 2011, commitment problems, Christia 2012, information problems, Nygård and Weintraub 2015: Wood and Kathman 2015, and strongly divergent preferences Bakke, Cunningham and Seymour 2012). Less is known about the characteristics that make rebel groups compatible partners and increase the likelihood that they pool forces, regarding military advantages they can gain from cooperation. As Gade et al. (2019) argue, the focus of the current literature has been primarily on why rebel organizations cooperate and compete (Bakke, Cunningham and Seymour, 2012; Metternich et al., 2013; Quinn, Joshi and Melander, 2019; Walter, 2019), but less is known with whom they do so (Christia, 2012; Gade et al., 2019; Dorff, Gallop and Minhas, 2020). In order to address this knowledge gap, in this paper we move away from an analytic and empirical lens on group and dyad-level characteristic, and instead take in the entire set of potential coalition partners by focusing on conflict theaters. Treating all rebel groups and pro-government militias

Date: January 30, 2021.

Martin Steinwand and Nils W. Metternich acknowledge support from the Gerda Henkel Stiftung (AZ 07/KF/13) and Nils W. Metternich is supported by the Economic and Social Research Council (ES/L011506/1). 
within a country, as well as the government, as part of one conflict theater allows for the analysis of strategic interactions between these actors and to derive and test predictions about the patterns of cooperation which are most likely to arise. To accommodate this shift in perspective, we make two conceptual innovations. On the theory side, we focus on the role of military synergies as source of affinities for cooperation between groups of civil war actors, and incorporate synergies into a formal model of coalition formation. Empirically we introduce the idea of tacit coalitions, which allows us to study emerging patterns of cooperative behavior across entire conflict theaters.

Many commentators have remarked a upon synergy effects before. For example, Christia (2012) notes that a coalition between various mujahedin groups in Afghanistan in 1985 "improved their battlefield performance that allowed them to capitalize on the economics of scale of their interactions." (p. 110) Akcinaroglu (2012) formalizes the idea of synergies as providing economies of scale when two or more groups pool their military capabilities. We start with the same idea, but pay attention to characteristics that provide some groups of actors greater synergies from cooperation than others. Actors join coalitions with the main objective to win an armed contest. Synergies arise when a coalition's military capabilities are greater than the sum of capabilities of its constituent members. Importantly though, we argue that these economies of scale are not uniformly distributed, but vary between specific pairs and groups of actors. To be able to analyze how these dyadic and group-specific synergies translate into battlefield coalitions, we develop a multi-actor formal model. The model takes into considerations strategic interactions across all actors, generates predictions for feasible coalition profiles across an entire conflict theater, and allows us to analyze how these predictions vary with different distributions of synergy-linkages and military capabilities between actors.

The dyad and group-specific view of synergies also allows for infusing the abstract concept of military synergy with empirical content. We use this innovation to explore the role of ethnic ties and geography in explaining battlefield coalitions, thus contributing to the literatures on these topics. For geography, we investigate how moving from proximity to remoteness of potential coalition partners spans a trade-off between ease of coordination and engaging the opponent over a larger area of the battlefield (Boulding, 1962, Gates, 2002). Regarding ethnicity, we look at a similar dynamic, where ethnic proximity may facilitate coordination (Strachan, 2006; Lyall, 2010), but bringing a larger number of ethnic groups into the fold promises to unlock additional resources and 
serves to avoid pitfalls of ethnic infighting (Krause, 2017) and avoids outbidding dynamics (Bloom, 2004).

On the empirical side, we introduce the concept of tacit coalitions. Tacit coalitions do not require a formal alliance relationship between actors. They arise when actors simultaneously fight the government (or a coalition containing the government) while foregoing any infighting. Conceptually, this approach recognizes the empirical observation that despite strong incentives to realize gains from cooperation, formal alliances between rebel groups or other civil war actors are surprisingly rare. Looking instead at tacit coalitions allows for taking in theater-wide conflict dynamics that otherwise could not be studied. We thus consciously treat instances of parallel fighting as coalition behavior, even if there are no formal or observable coordination efforts. We believe that this approach closely captures the battlefield reality of civil war, where information is generally scarce, and fighting decisions need to be based on available observations of movements and actions of other actors. Since our hypotheses make very specific predictions about the characteristics of coalition partners and find support in the data, we are confident that the tacit coalition concept is suitable tool to distinguish meaningful coalition patterns from randomly arising parallel fighting activity.

Beyond the immediate focus on the identities of groups that make for suitable coalition partners, the paper makes a number of additional contributions. Although there exists extensive alliance theoretical work in the context of international conflict (e.g. Waltz, 1964; Organski, 1958; Waltz, 1979; Wagner, 1986; Niou, Ordeshook and Rose, 1989, Fordham and Poast, 2016), similar dynamics have received less attention in civil war (important formal works on coalition behavior are not civil-war specific, Esteban and Ray 1999, 2008, Niou and Tan 2005). This paper brings a conflictsystem perspective to the study of civil war, and uses a multi-actor conflict game to make testable predictions how variation in the theater-wide distribution of synergies and military capabilities affects overall patterns of coalition behavior.

The paper also contributes to a burgeoning literature on coalition formation in non-instiutionalized settings, not only in civil wars (Christia, 2012). It provides a template of how to combine a multiactor formal model with a k-adic empirical analysis. This can be applied to coalition behavior in areas such as state-building (Driscoll, 2012), terrorism (Phillips, 2014; Nemeth, 2014; Conrad and Greene, 2015), and in autocratic regimes (Acemoglu, Egorov and Sonin, 2008; Francois, Rainer and Trebbi, 2015, Bormann, 2019). 


\section{Who Joins With Whom? Theoretical CONSIDERATions}

Only a few existing works directly address the question of who makes good coalition partners for rebel organizations. These works can be distinguished between those that focus on power relations (e.g. Christia, 2012) and those focusing on ideological proximity (e.g. Gade et al., 2019) 1. While our approach naturally incorporates a power relations perspective, it allows for inter-group linkages such as ideology to influence military synergies.

Christia (2012) provides one of the most comprehensive theoretical accounts of how power relations shape which types of rebel organizations can sustain alliances. She assumes that rebel organizations form, ideally, minimal winning coalitions to 1) win the war and (2) maximize political control after the fighting has ended. The main challenge to cooperation is a commitment problem when some actors are concerned to be exploited by stronger coalition partners. The expectation of being weak in a current coalition provides incentives to switch to other coalitions with more power balance. Christia (2012) also argues that these power dynamics trump identity concerns in coalition formation, which can be constructed after the rebel organizations have joined. We follow this lead and build our theory of coalition behavior on the notion that rebel organizations combine forces to improve their battlefield success. We also incorporate the idea that coalition members are at risk of continuing infighting after capturing the government. However, as we discuss below, our modeling exercise shows that even a small reduction of the risk of infighting has important implications for which rebel organizations make suitable coalition partners.

Gade et al. (2019) challenge the view that cooperation among rebel organizations is purely driven by power dynamics and emphasize the importance of ideology (see also Seymour, Bakke and Cunningham, 2016). Ideological proximity should increase military cooperation, because it clearly defines the conflict cleavages and provides a common vision of the post-conflict order. Gade et al. (2019) also formulate slightly different expectations about power dynamics. Fighting against a powerful government that threatens the survival of rebel organizations fosters small and balanced coalitions to decrease coordination problems, while the absence of a strong government threat enables strong rebel organizations to accept coalitions with many small partners and accepting higher coordination costs for gaining control over smaller parties. Our approach allows for ideological proximity and other inter-group linkages to enter the analysis via their effect on military synergies that

\footnotetext{
${ }^{1} \mathrm{~A}$ third line of work does not look at group characteristics, but highlights the role of outside sponsors in fostering coalition behavior (Popovic, 2018).
} 
rebel organizations can realize in coalitions. Instead of ideological distance, we focus on the role of ethnic ties and geographic distance. Going beyond Gade et al. (2019), our model can show how the distribution of linkages among actors affects the power-based coalition logic.

\subsection{Contest Games and Coalition Building}

We develop a formal model of coalition formation. Formalization helps us to keep track of the logic of interactions between more than three actors, and thus allows for a conflict theaterwide perspective on coalition formation. The starting assumption of our modeling approach is that conflict actors' main objective is to win the armed contest. Actors recombine forces to realize synergies, which can result from a number of factors, including ethnic ties, and geographic location. This means that coalitions do not only pool military capabilities, but they also are instrumental in unlocking otherwise unrealized gains. In other words, synergies represent positive economies of scale to the use of force and gives rise to otherwise unexpected coalitions.

We draw on the rich literature on conflict games (also known as contest games, Dixit, 1987, Hirshleifer, 1988, 1995, Garfinkel and Skaperdas, 2007). The conflict game framework also has been used to investigate contests with multiple actors (Esteban and Ray, 1999, 2008; Niou and $\operatorname{Tan}, 2005)$. It assumes that actors are fighting over an incompatibility and investigates if effort is exerted efficiently:2

An important modeling decision when formally studying coalition behavior is the rule by which coalition members allocate the spoils from their joint efforts. Civil war is beset by commitment problems, and coalition members may find it difficult to make binding commitments to honor any agreement on how spoils should be shared. In an ideal-typical world, without any commitment ability, coalition partners are likely to turn on each other to divide the spoils of victory, resulting in continuing conflict (Tan and Wang, 2010). The expected division of spoils therefore strictly reflects

\footnotetext{
${ }^{2}$ The analytic focus on coalition behavior on the battlefield means that we leave some questions unexplored. In particular we are not taking on multi-actor bargaining prior to conflict, and therefore the causes of conflict onset. One reason for this is that once fighting starts, issues central to conflict bargaining become less relevant for actors' choices. For example, battlefield actions reveal private information about actor resolve and capabilities. Commitment problems that originate from uncertainties about rebel strength are resolved, as rebel organizations reveal their ability to organize effective fighting forces. We are interested in the effects of capabilities and military synergies on coalition behavior, which makes the conflict stage a natural setting for our inquiry. In addition, though perhaps less sanguine, conflict games sidestep analytical challenges that arise in multi-player bargaining, such as large equilibrium spaces and conflict equilibria with complete information, though we still encounter some of those problems, as discussed below. Ray (2007/section 4.4.3) provides a good discussion of the issues involved, based on a little known result due to Herrero (1985). Having noted this limitation, the analysis presented in this paper still can help to inform future research on conflict initiation, as it sheds light on which coalition choices and associated payoffs negotiators can anticipate should bargaining break down.
} 
the relative power of coalition partners. This is an overly pessimistic scenario, as in reality few civil wars feature continuing infighting and only end once one rebel organization (or the government) remains. As our analysis will show, a strict division of spoils according to relative power also correspond to a situation where belonging to any coalition is better then going alone. Obviously this does not match the empirical reality of coalition behavior. To gain analytic traction, we explore what happens if coalitions can entail even a small degree of commitment. We follow Ray (2007) and treat coalition membership as being built on mutual assent of all coalition members and a lack of infighting, even if just temporary, without negating the non-cooperative nature of the conflict environment (Ray, 2007). The possibility of deviating from sharing based on strict relative power narrows the range of feasible coalitions, and we find that powerful actors become more reluctant to join with weaker actors, resulting in more evenly balanced coalitions.

\subsection{Military Synergies}

A central feature of our conflict system theory is the focus on military synergies as driver of coalition behavior. Synergies and economies of scale are synonymous and refer to a situation in which a coalition's military capabilities are greater than the sum of capabilities of its constituent members.

Scholars have identified two major areas that affect the military success of rebel organizations in civil war ${ }^{3}$ These are geography and collective action problems. Geography has been studied from the perspective of military advantages that remote areas such as mountains provide to rebel groups. Collective action problems refer to the ability of rebel organizations to induce its members to expose themselves to the risk of personal harm in the service of group goals. Gates (2002) provides a useful conceptualization that encompasses both aspects. He casts potential members of a rebel group as situated in a latent space, consisting of ethnicity, ideology, and geographic location. Fighting effectiveness is a function of distance between the position of individual fighters and the rebel group as a whole in this space, with larger distances resulting in greater collective action problems.

\footnotetext{
${ }^{3}$ The tacit coalitions formed in civil war between armed organizations share some similarities, but also differ in important ways from how governments form coalitions involving national armed forces during interstate war. While military synergies play an important driving role for the formation of coalitions in both scenarios, national governments have a greater ability to coordinate military actions (Morey, 2016) and provide side payments to potential coalition partners (Wolford, 2015). At the same time they also face potential disagreements on a wider range of policy objectives (Wolford, 2015). In contrast, the ability of rebel organizations to realize synergies is tied to a narrower range of factors, such as geographic distance and ethnicity discussed here. They also typically either fight for control of or independence from the central government and command fewer resources to affect side payments to other groups.
} 
We draw on this reasoning to conceptualize military synergies in rebel coalitions as a function of geographic space and ethnicity $]^{[}$Starting with geography, there is strong evidence that remote locations and mountainous terrain offer military advantages to rebel organizations (Buhaug, Cederman and Rød, 2008, Cunningham, Gleditsch and Salehyan, 2009). This empirical pattern confirms the important conceptual idea that the central government's ability to project military force diminishes with geographic distance (the so called Loss of Strength Gradient, Boulding, 1962). From the perspective of military cooperation between rebel groups, this suggests that geographic distance produces synergies in the groups' fighting effectiveness. Opening up a second, remote front divides the opponent's forces and capitalizes on loss of strength associated with having to operate in geographically apart conflict theaters. However, the insights from Gates (2002) suggest a trade-off, as commitment problems also increase with distance. Forming a tacit coalition and fighting in a coherent manner requires a minimum of coordination, which also becomes more difficult as distance increases $5^{5}$ We should therefore expect military synergies to relate to distance in an inverted $\mathrm{u}^{-}$ shape. For groups that are geographically relatively close, larger distance increases synergies. But this effect reverses as distances grow too large, and coordination becomes increasingly difficult.

The second source of synergies is ethnicity and we focus particularly on the role of identity for recruitment and support. A prominent strand in the literature suggests that cooperation between ethnically aligned rebel organization should help unlock synergies. Ethnicity and identity can be mobilized as political cleavages, which allows armed groups to leverage them for recruitment purposes. This is especially the case if political cleavages are characterized by economic and political grievances between included and excluded groups (Wucherpfennig et al., 2012). Identity markers also facilitates identification of potential supporters and reduces collective action problems, as similar policy preferences, ideological coherence (Strachan, 2006), and shared social networks allow for better coordination and monitoring (Lyall, 2010).

Yet there are important arguments that shared ethnic ties also could serve to undermine cohesion within coalitions, thereby lowering synergies. Competition dynamics can lead to fragmentation (Cunningham, Bakke and Seymour, 2012), which in turn impedes unified and successful coalitions Krause, 2017). In addition, rebel coalitions that successfully operate across ethnic cleavages might be able unlock additional synergies not available to groups from same ethnic background. For

\footnotetext{
${ }^{4}$ Ideology is more difficult to measure. We therefore concentrate on the other two aspects.

${ }^{5}$ In a similar vein, Weisiger (2016) finds that coalitions between states in interstate war are more likely to disintegrate if one coalition member fights in a geographically remote area.
} 
example, coalitions across ethnic groups are able to expand their recruitment base and can potentially do this across social classes in instances where ethnicity is associated with social status (?). Likewise, in communities with inter-dispersed ethnic settlement patterns, cross-ethnic coalitions might be better able tap into civilian support. Note that these arguments are different from (Gade et al. 2019), who stress coordination advantages of common identities and also (Christia, 2012), who largely discounts the role of identity in coalition formation.

Ultimately it is an empirical question whether ethnic similarity enhances or reduces military synergies from cooperation between armed groups. Our approach is able to shed light on this question in a multi-actor setting, while also simultaneously accounting for the role of power dynamics.

\section{A Theory of Conflict Coalition Behavior}

In this section, we present our theoretical model of coalition behavior between conflict actors. There are $n$ actors $i$ which together form the set of actors $N$ (including rebel organizations, progovernment militias, and the government). Each actor has military capability $m_{i}>0$. If two actors $i, j$ form a coalition $g$, their capabilities are added up according to the joint force function: $\left(m_{i}+m_{j}\right)^{\alpha_{i j}}$. Synergies arise if the parameter $\alpha_{i j}>1$ (superadditivity). ${ }^{6}$

When coalitions have more than two members, there could be synergies that are subject to higher order effects (e.g. three-way interactions). Since we don't have any theoretical expectations about the nature of such effects, we average across all binary synergies for pairs of actors in the coalition. A coalition $g$ therefore has an aggregated military capability of

$$
\left.\left(\sum_{i \in g} m_{i}\right)^{1 /(|g|-1) \sum_{\{i, j\} \in g} \alpha_{i, j}} \text { (joint force function of coalition } g\right)
$$

where $|g|$ is the number of actors in coalition $g$.

An actor's utility is a function of how it expects to perform on the battlefield, which in turn depends on the distribution of capabilities in the entire conflict, including the aggregate capabilities of the actor's coalition, and the capabilities of opposing actors and coalitions. The arrangement of coalitions in the conflict theater is denoted as coalition profile $G=\left\{g_{1}, \ldots, g_{k}\right\}$, with individual coalitions in $G$ denoted as $g_{r}$. The probability of battlefield success for any coalition $g_{r}$, denoted as $P_{g_{r}}$, is governed by the conflict success function, which translates aggregate military capabilities into winning probabilities according to

\footnotetext{
${ }^{6}$ The notion of superadditivity in contest games with coalitions was introduced by Skaperdas (1998).
} 


$$
P_{g_{r}}=\frac{\left(\sum_{i \in g_{r}} m_{i}\right)^{1 /\left(\left|g_{r}\right|-1\right) \sum_{\{i, j\} \in g_{r}} \alpha_{i, j}}}{\sum_{r \in G}\left(\sum_{i \in g_{r}} m_{i}\right)^{1 /\left(\left|g_{r}\right|-1\right) \sum_{\{i, j\} \in g_{r}} \alpha_{i, j}}} \text { (conflict success function). }
$$

Thus, the probability of coalition $g_{r}$ winning is a function of its military capabilities relative to the total capabilities of all coalitions in conflict theater $G$. Holding the prize over which actors fight to be constant at 1,7 equation 2 also gives $g_{r}$ 's expected utility of fighting. 8

For utilities of individual actors $i$, we need to consider how the spoils from victory are distributed among members of the winning coalition. We discussed above the two ideal typical scenarios, sharing according to relative power as a reflection of payoffs from future infighting among coalition partners (Tan and Wang, 2010) ? $^{9}$ and equal sharing of spoils among all coalition members as an expression of the ability to commit to binding agreements. The following expected utility formulas show how the different rules divide the spoils from fighting as part of a specific coalition $g_{r}$ :

$$
\begin{aligned}
& \text { Relative Power : } U_{i}\left(g_{r} \mid i \in g_{r}\right)=\frac{m_{i}}{\sum_{j \in g_{r}} m_{j}} P_{g_{r}} \\
& \text { Equal Sharing : } U_{i}\left(g_{r} \mid i \in g_{r}\right)=\frac{1}{\left|g_{r}\right|} P_{g_{r}} .
\end{aligned}
$$

\footnotetext{
${ }^{7}$ The conflict success function also illustrates that in conflict games, superadditivity works differently than in cooperative game-theoretic treatments of coalition behavior (e.g. Bloch, 1997). In the latter, typically superadditivity directly increases the utility of coalition members, which provides incentives to form a grand coalition. In our setup, superadditivity affects payoffs only through increasing the probability of winning, while the utility of capturing the prize is fixed. As a result, marginal contributions of adding coalition members start declining once a coalition becomes too big, limiting which coalitions are feasible in the equilibrium analysis.

${ }^{8}$ Deviating from traditional conflict games, we treat effort as a constant function of military capabilities. This implies an assumption that there is no free-riding on part of coalition partners. This simplification allows us to focus on coalition behavior. There are also two substantive justifications. First, synergies can only be realized if actual effort is expended. Free-riding incentives arise when a coalition partner's actions can be substituted for own actions. This is manifestly not the case if there are synergies. Second, tacit alliances are informal in nature and civil war is a low-information environment. Under these conditions, effort expended by partners is not easy to establish and the ability to free-ride on these efforts is reduced (Sandler, Sterbenz and Posnett, 1987).

${ }^{9}$ Note that we deviate from Tan and Wang $(2010)$ by ignoring the possibility of coalition formation during infighting between winning coalition members. Analytically, their approach constitutes an equilibrium refinement. We ignore this refinement out of analytic convenience. However, there is also a strong case for cognitive limitations of militant groups regarding future coalition behavior that is due to the 'fog of war', i.e. fundamental uncertainty that shrouds possible battlefield outcomes. Anecdotal support for this limitation comes from accounts of how coalition partners shift the perceptions of their allies from partners to potential threat, once joint victory comes into sight (Christia, 2012 ).
} 
In reality, we expect sharing rules to fall somewhere in the middle, and likely fairly close to the relative power rule. Mixtures between the extremes are achieved by taking a convex combination of the boundary cases 10

\subsection{Structure \& Strategies}

The model treats coalition formation as coordination game in normal form. A strategy for actor $i$ is a choice of an unrealized coalition $\gamma$ that contains $i$ itself, i.e. $\gamma \subseteq N, i \in \gamma$. A realized coalition is called $g$, and the set of all realized coalitions form a coalition structure $G$, where $G$ perfectly partitions $N$. A coalition $g$ is realized only if all members contained in $g$ ascend to its membership. In other words, all members of $g$ must propose $\gamma=g$. Otherwise they default to fighting by themselves, i.e. singleton coalitions. To illustrate this, the coalition $g_{r}=(A, B, D)$ only forms if $A, B$, and $D$ each propose $\gamma=(A, B, D)$, but not if either $A, B$ or $D$ propose any $\gamma \neq g_{r}$ (even if $\gamma \subset g_{r}$, the prosed coalition is a strict subset of $g_{r}$ ).

Analyzing coalition formation as coordination problem sets aside the interactions between armed groups that precede coalitions, such as informal communications, negotiations, and displays of threat. These interactions are typically difficult to observe and potentially very complex. Instead the analysis characterizes which set of coalitions is feasible on the basis of military capabilities and synergies, without generating point predictions which particular coalition will be realized at any given point in time. As important conceptual implication, the coordination game approach captures the self-enforcing nature of cooperation in a conflict environment. We rely on Nash equilibrium as solution concept, where larger groups of actors only cohere as a whole when no single group has an incentive to go it alone. Hence, coalition behavior is not 'baked into' the modeling assumptions 11 This setup also allows for the incorporation of cooperative elements, such as the notion of enforcability of contracts between coalition members. This is similar to how Ray (2007) conceptualizes mutual assent of all coalition members as prerequisite to exploring the consequences of a cooperative setup (transferable utility) in a non-cooperative bargaining environment.

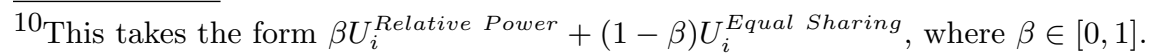

${ }^{11}$ Refinements such as Strong Nash equilibrium or Coalition-Proof Nash allow for multilateral deviations, but rely on differing degree of cooperative behavior (communication) prior to play. In addition, although we don't consider them in the analysis, the Nash approach is also particularly justified if there are 3rd order network effects that give rise to non-linearities in which military synergies are aggregated across coalition members. For example, a coalition between two actors might only be beneficial in the presence of a third actor, but not if this third actor is absent.
} 


\section{Analyzing Coalition Behavior With Synergies}

The key ingredients of our systems theory of coalition behavior are capabilities of armed groups and synergies that help unlock military advantages. To analyze their effects, we use the formal model to simulate coalition choices while varying these parameters ${ }^{12}$ We examine the four players case 13

For the power distribution, the resulting grid features 849 different profiles $4^{14}$ It is created by incrementing the capabilities of all actors in 5 percent steps, and collecting all combinations that respect the constraint that total power must sum to 100 percent. The synergy parameter $\alpha$ varies between 1.01 and 1.20, in 0.01 steps (we begin with homogeneous synergies across all groups). The choice of range of $\alpha$ follows pragmatic considerations. At the upper end, with $\alpha=1.2$, synergies increase the military capability of an unopposed coalition that captures 50 percent of raw capabilities to about 67 percent ${ }^{15}$ This 17 percentage point gain represents a 28 percent increase in fighting power. While ultimately arbitrary, larger synergy effects appear unrealistic.

An additional choice involves the sharing rule. We find that using the pure relative power rule (eq 3), any coalition becomes feasible as a Nash equilibrium. This is because it is always better to combine forces, reap aggregate gains from synergies, and then share according to relative power, than going it alone and gaining a payoff reflecting relative power without the gains from forming a coalition. In the real world, obviously not every possible coalition is equally likely to form. However, as we describe in detail in the appendix, even small deviations from the relative power rule reduce the equilibrium space. For generating predictions we go to the other extreme and assume equal sharing. This assumption is empirically highly unrealistic, but it cuts down the equilibrium space the most and therefore generates the sharpest predictions. In reality, sharing rules within tacit coalitions will be much less re-distributive, even if they do involve a small element of redistribution. Thus coalition patterns should still follow the logic of our theory, but will be less pronounced. This in turn will attenuate our ability to detect them empirically. Thus, our theoretical approach

\footnotetext{
${ }^{12}$ We use a simulation approach to overcome the lack of closed form solutions to the comparative statics, which arises from the non-linear nature of the utilities.

${ }^{13}$ Despite its simple setup, the coalition formation game presents considerable computational hurdles. Its strategy space is of size $2^{n(n-1)}$ and therefore grows exponentially in the number of players. With $n=5$ there would be already 1,048,576 strategy combinations, hence the focus on the 4 actor case. This is also substantively justified, as the average number of conflict actors in our data ranges between 3 and 4 . We use the Gambit software to retrieve pure strategy equilibria to the game (McKelvey, McLennan and Turocy, 2013).

${ }^{14}$ Keeping track of actor identities, e.g. a power profile of $(0.4,0.2,0.2,0.2)$ is different from $(0.2,0.2,0.4,0.2)$.

${ }^{15}$ Unopposed in the sense that no other coalition forms.
} 
generates predictions that are subject to difficult empirical tests. It is worth pointing out that we do not seek to empirically identify the sharing rule itself.

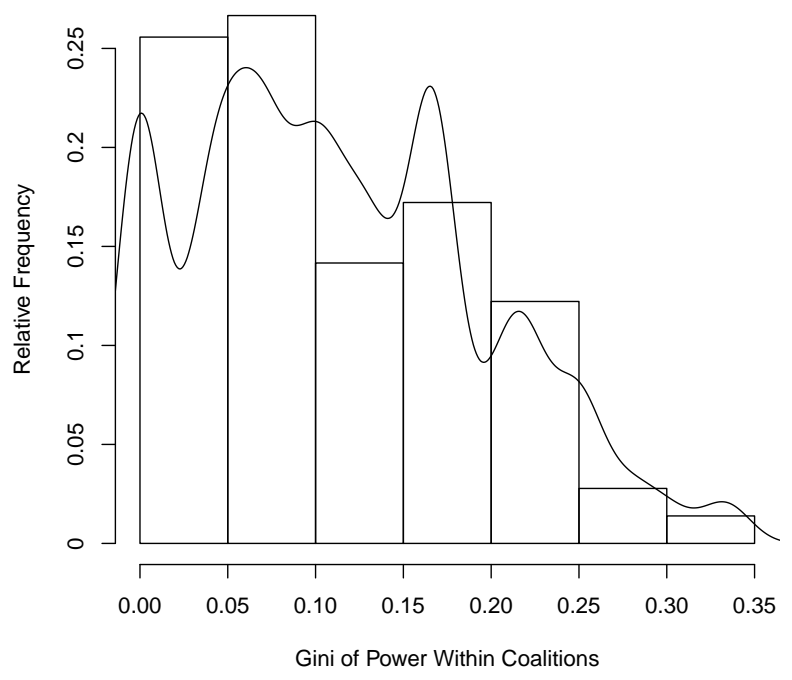

Figure 1. Within Coalition Power Balance. Based on Gini coefficient of power shares within equilibrium coalitions.

\subsection{Symmetric Synergies}

We summarize the results of the simulations starting with a focus on the distribution of power, assuming symmetric synergies for all armed groups ${ }^{16}$ Figure 1 shows how common different power distributions are in feasible coalitions. For each coalition that can form in equilibrium, we calculate the Gini coefficient of the power distribution of its members. The Gini coefficient ranges between 0 and 1, with higher values indicating greater inequality. The results show that highly unequal coalitions (with Gini coefficients of 0.25 and higher), are much less common than more equally balanced coalitions. To drill deeper into these results, we evaluate coalition behavior of individual armed groups. Details are reported in the appendix. We find that actors of equal power are more likely to be part of coalitions, because they do not face any conflicts over the distribution of the spoils of victory. This arises because for sufficiently large actors joining forces and realizing synergies does not compensate for sharing even a small part of the spoils of victory. The tendency of individual

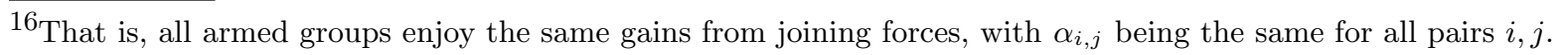


groups to seek coalition partners of similar size explains the scarcity of relatively unbalanced coalitions at the aggregate level shown in figure 1. We therefore arrive at the following prediction:

Hypothesis 1: Coalitions are less likely to form as power asymmetries among coalition members increase.

What about the absolute size of coalitions? Riker's size principle (Riker, 1962) suggests that there are tradeoffs between maximizing the chances of winning (which would be 1 in the boundary case, the grand coalition), and having to share the spoils of victory. Our theory generates similar predictions, but for subtly different reasons.
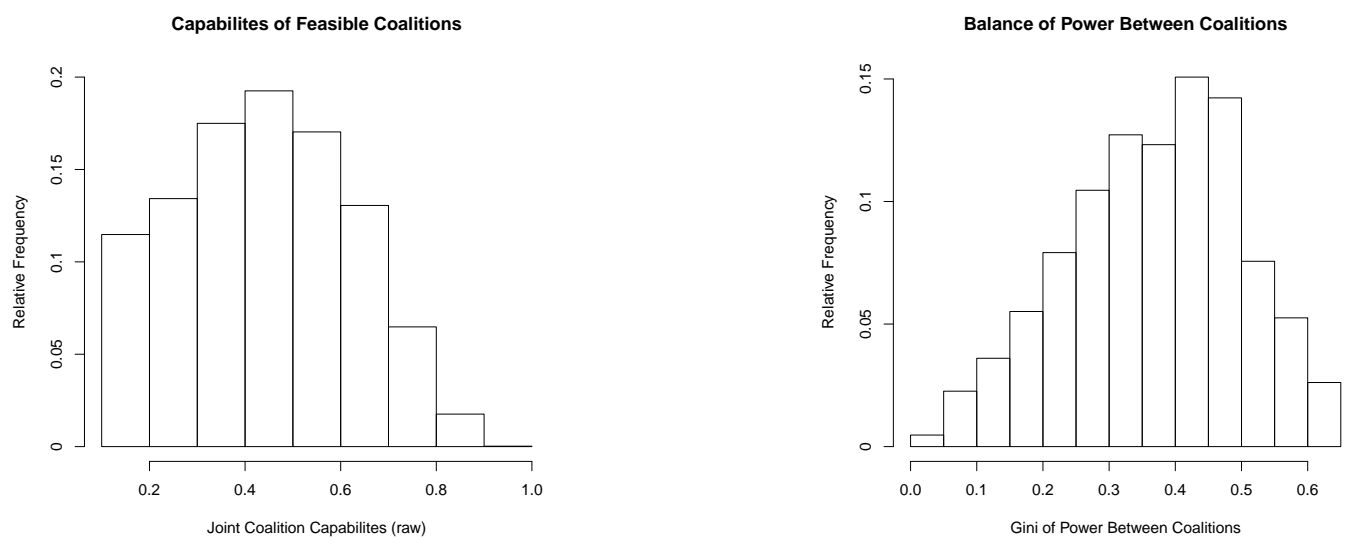

Figure 2. Coalition Capabilities and Balance of Power Between Coalitions. Left panel is based on sum of power shares of all equilibrium coalitions (excluding singletons). Right panel is based on Gini of power shares of coalitions in an equilibrium coalition profile.

The left panel of Figure 2 shows how the joint capabilities of all feasible coalitions are distributed ${ }^{17}$ The average lies at 46 percent of system-wide capabilities (34\% when not counting singletons), and coalitions which combine more than 50 percent of capabilities become increasingly rare. However, such supersized coalitions still account for about 38 percent of what is feasible in equilibrium (19\% without singletons), more than would be expected under strict operation of Riker's size principle. Still, empirically we would expect supersized coalitions to be rare. We also

\footnotetext{
${ }^{17}$ This is the 'raw' sum in the sense of not accounting for synergies. Singletons are excluded.
} 
observe that weaker coalitions also occur with less frequency. This results from the pressures that turn groups of equal power into more likely coalition partners, as discussed in hypothesis 1 .

The standard account for why supersizing of coalitions is rare revolves around the idea of balancing. For example, Fordham and Poast (2016) find that alliances between state actors are most likely to form when they combine around 30 percent of system-wide capabilities. They argue that "[a]n alliance of this size wold have ... the capabilities to compete with any state in the system." (p. 857) In contrast, our theory suggests that supersizing is rare because of the limited appetite of large actors to join forces with smaller ones. The right panel in Figure 2 illustrates that theaterwide balancing is relatively rare. It is based on entire coalition profiles, and shows that coalitions frequently face much weaker or stronger adversaries. In other words, it pays to join forces even if doing so does not bring the chances of winning close to 50 percent. To illustrate, the median Gini coefficient is 0.38 , which corresponds to division of power of 12.5 to 87.5 percent (if there are only two parties).

As empirical prediction, we take away from this discussion that both small and large coalitions should be relatively rare, but we don't expect that there is a well-defined cutoff beyond which coalitions don't form.

Hypothesis 2: Coalitions are most likely to form for a middle range of joint capabilities and less likely to form for low or high joint capabilities.

4.1.1. Asymmetric Synergies. We now look into the role of military synergies in more detail. The analysis so far assumed that all military groups can realize identical synergies, regardless of coalition partner. Turning attention the identity of actors, we now allow specific pairs of military groups to generate greater synergies than other pairs. Technically, this involves assigning heterogeneous values of the synergy parameter $\alpha$ across actor pairs.

We evaluate equilibrium coalition behavior for 4 different scenarios. With $n=4$ players, there exists 6 pairs of players, each pair with its own $\alpha$. As baseline scenario, all 6 values of $\alpha$ are set to 1.1 (the homogeneous case). We then give player 1 higher synergies with a varying number of other players, ranging from one other player to all three of them. For each such high synergy link, $\alpha$ is set to 1.2 


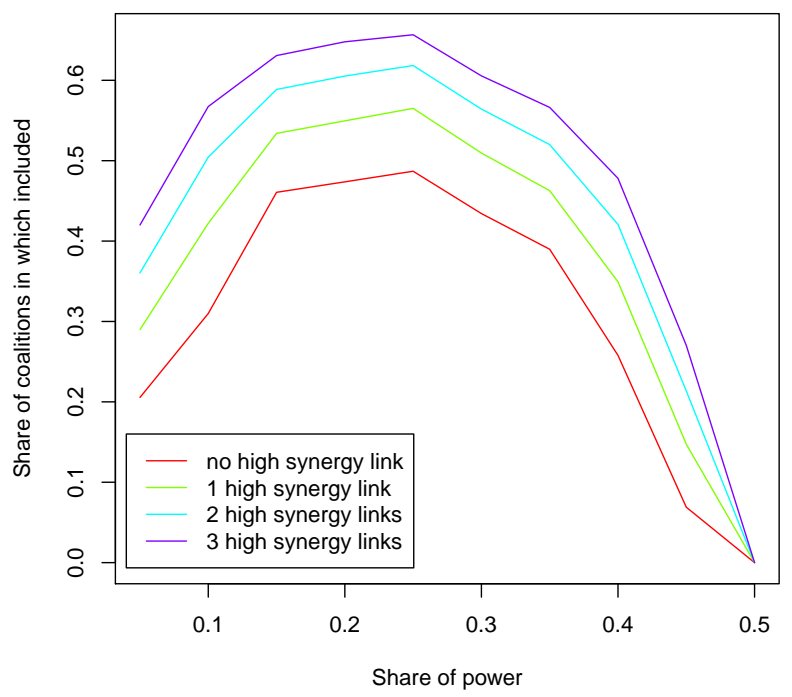

FigURE 3. Illustration of how heterogeneous synergies affect whether an actor forms part of a coalition. It shows the share of all feasible coalitions that include player 1 , as a function of player 1's relative power. The number of high synergy links $(\alpha=1.2)$ and low synergy links $(\alpha=1.1)$ to other actors varies.

Figure 3 does not look at aggregate coalition behavior, but focuses on a specific armed group, called player 1 . It illustrates how likely player 1 is to enter into coalition with other actors. The graph shows which share of all equilibrium coalitions contain player 1, as a function of player 1's power and its possession of high synergy links to other players. Endowing player 1 with more high synergy links has a clear effect, as the player gets included into a greater share of coalitions. The advantage of high synergy links is substantively large, and the most so when player 1 has low power. With 10 percent of power resources, moving from no to one high synergy link increases the share of feasible coalitions in which player 1 is included by 10 percentage points, from 31 to 41 percent. While less in absolute terms, relative gains are even greater when it is the least powerful, holding only 5 percent of capabilities. In this scenario, the participation share increases by 8.5 percentage points from 20.5 to 29 percent, constituting a 41 percent gain. Going in the different direction, as player 1 amasses more power, the benefits from high synergy linkages decrease. They remain noticeable though until player 1 reaches 50 percent of power resources. After this point, joining coalitions does not lead to additional utility gains and synergies stop to matter. Adding a second or third high synergy link produces additional participation gains, but the effect is decreasing in size. Overall, the simulation produces a clear expectation that in an conflict system with heterogeneous 
synergies, those actor pairs that have the highest synergies and who therefore can realize the most military advantages are most likely to be part of the same coalition. This generates a system-level prediction about coalition behavior:

Hypothesis 3: With increasing differences in synergies, actor pairs with higher synergies are more likely to form a coalition.

The next section develops empirical tests of the hypotheses and presents statistical results.

\section{EMPIRICS}

The empirical section investigates conditions under which tacit coalitions are realized in the context of civil war and their internal makeup. We test our propositions on the coalition level using a k-adic approach (Poast, 2010). The analysis explores the role of relative strength and heterogeneity in synergies for determining which rebel groups form, what we define as, tacit coalitions.

\subsection{Outcome variable: Tacit coalitions}

While we frequently observe coalition behavior among rebel organizations, formal coalitions are rare. For example, the Uppsala Conflict Data Project (UCDP) only identifies four coalitions in Africa between 1989 and 2014 that are based on a codified and public commitment to work together. Similarly, Akcinaroglu (2012) finds that formal rebel coalitions are relatively rare. Hence, to measure coalitions we take a behavioral approach (Metternich et al., 2013). We use the UCDPGeoreferenced Event Data version 18.1 (UCDP-GED, Sundberg and Melander, 2013), which covers violent events during civil conflicts in Africa (1989-2017). For each violent event, UCDP-GED identifies Actor A and B that are involved in fighting activities. We begin by identifying all actors that were in involved in state-based conflict, i.e. the government and all rebel organizations fighting a government. We then extract all events that involve the identified actors and measure which actors fought another actor in the same month.

To illustrate our coding, imagine three rebel organizations $(A, B, C)$ that are active against the government $(G)$. They can form the following potential coalitions: $A, B, C, A B, A C, B C, A B C$. If $A$ and $C$ fight the government in month $t$ and $B$ does not fight the government, tacit coalition $A C$ is realized. We then aggregate the monthly realizations to the yearly level. Thus, our dependent variable is a count ranging from 0 to 12 , indicating the number of months in which a tacit coalition 


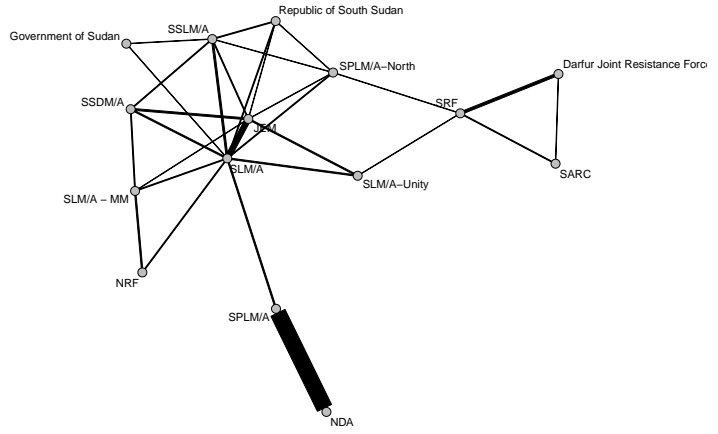

(A) Sudan

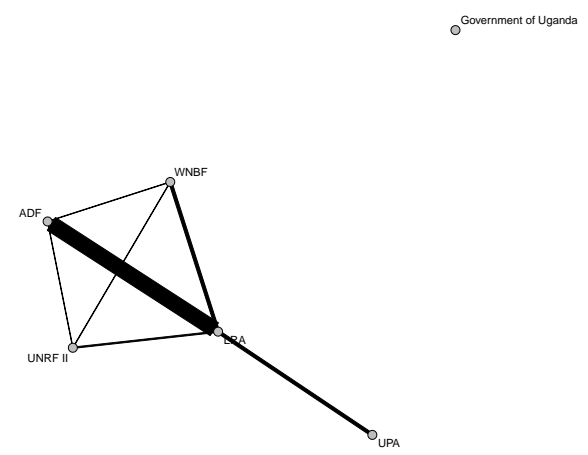

(B) Uganda

Figure 4. Tacit coalitions: Having fought the same actor in a particular month. Number of months of commonly fighting an other actors aggregated for 1989-2017. Edge thickness represents realized coalition months.

has been realized. We identify realized coalitions through the concept of subgraphs, allowing for multiple coalitions to be realized in a particular month. If $A$ and $C$ fight the government in month $t$ and $B$ would join the government $G$ to fight against $C$, tacit coalitions $A C$ and $B G$ are realized.

For a visualization of the dependent variable, we aggregate the number of months that two actors form a tacit coalition over the total observation period. While in the analysis the dependent variable varies over time, the aggregate visualization helps establish face validity of our measure. Figure 4 shows the aggregate number of tacit coalition months for Sudan in the left panel and Uganda on the right. In Sudan, the rebel organizations that have fought the government most often in the same month are the National Democratic Alliance (NDA) and the Sudan People's Liberation Movement/Army (SPLM/A). In Uganda, this applies to the Allied Democratic Forces and the Lord's Resistance Army (LRA). In both countries there is evidence that these tacit coalitions were underpinned by alliance-like relationships. 18

While our behavioural approach to the measurement of coalitions has the advantage of picking up on non-formal coalition behavior across a large number of cases, there are some limitations that need to be made explicit. First, there is the risk that some tacit coalitions are 'accidental' coalitions

${ }^{18}$ There is widespread agreement that the NDA and the SPLM/A acted as allies in Sudan's civil war (Young, 2005). The ADF and the LRA were both supported by Sudan (Prunier, 2004) and there are several reports of cooperation between the two rebel organizations. Source: Sahara Reporters, "Is the War on Terror Shifting to Africa?", 10/26/2011, accessed on 28 March 17 at http://saharareporters.com/2011/10/26/war-terror-shifting-africa Uganda Radio Network, "LRA and ADF Rebels Form an Alliance", 3/26/11, accessed on 28 March 17 at http: //ugandaradionetwork.com/story/lra-and-adf-rebels-form-an-alliance. 
as actors might just happen to fight the government in the same month. However, it seems unlikely that systained patterns of fighting the same actor in the same month arise purely by chance. We therefore take such patterns as indicative of a willingness to jointly bring down the opposing force. Second, the GED data does not allow us to identify the directionality of attacks. Thus an attack of the government against two rebel organizations in the same month would make them a tacit coalition in that month. While we agree that this is potentially problematic for validity purposes in a particular month, we argue that over time even common attacks by the same actor demonstates that two or more actors are willing to jointly withstand another actor and not separately enter an agreement with this actor.

\subsection{Estimation}

Our theoretical framework highlights that tacit coalition behavior is driven by both actor and coalition characteristics. To account for this, we implement a k-adic research design (Poast, 2010), which allows us to to include characteristics of potential coalitions. This approach is more appropriate than a complete network perspective, because by design we are dealing with local coalitions that are not connected beyond country boundaries. In addition, local coalitions are relatively small, meaning that the number of potential coalitions is fairly small in comparison to other applications. Hence, we are not confronted with rare event problems that can be challenging for other k-adic research designs. As our dependent variable is a time varying count variable, we estimate negative binomial models and capture time-dependency with lagged dependent variables and unobserved country-specific factors with random effects.

Overall, our analysis includes 482 observations pertaining to 328 potential tacit coalitions. We only include potential coalitions if there are at least three actors (including the government) active in a given country. Table 1 presents both the distribution of our dependent variable and how often unique tacit coalitions are realized in our data.

\subsection{Explanatory variables}

Our theory suggests that tacit coalition behavior is a function of power relationships, overall coalition strength, and synergies. We expect that potential coalitions with equal distributions of power are more likely to be realized. Temporal change in this distribution should affect the formation and fragility of tacit coalitions, resulting in the empirical challenge of measuring the military power of rebel organizations over time. While there exist attempts to measure the military 
TABLE 1. The upper table shows the outcome variable distribution for tacit coalition years. The lower table provides information on how frequent particular coalitions are realized across the entire observation period (1989-2017).

(A) Outcome Variable: Months potential tacit coalition realized per year $(\min =0$, $\max =12)$

\begin{tabular}{ccccccccccccc}
\hline \hline 0 & 1 & 2 & 3 & 4 & 5 & 6 & 7 & 8 & 9 & 10 & 11 & 12 \\
\hline 5,125 & 248 & 79 & 49 & 32 & 26 & 18 & 9 & 5 & 6 & 4 & 4 & 2 \\
\hline
\end{tabular}

(в) Months a particular potential tacit coalition is realized across observation period.

\begin{tabular}{cccccccccccccccccccccccccc}
\hline \hline 0 & 1 & 2 & 3 & 4 & 5 & 6 & 7 & 8 & 9 & 10 & 11 & 12 & 13 & 15 & 18 & 20 & 23 & 24 & 26 & 27 & 34 & 47 & 48 & 50 & 51 \\
\hline 3,725 & 169 & 51 & 33 & 15 & 8 & 8 & 10 & 7 & 7 & 2 & 2 & 2 & 1 & 2 & 1 & 1 & 1 & 1 & 1 & 1 & 1 & 1 & 1 & 1 & 1 \\
\hline
\end{tabular}

power of rebel organizations (e.g. Cunningham, Gleditsch and Salehyan, 2009), these projects do not focus on variation over time. Therefore, we suggest a measure that draws on geographic data to infer rebel characteristics and conflict dynamics (Beardsley, Gleditsch and Lo, 2015; Greig, 2015).

To capture the military strength of rebel organizations, we calculate the geographic area in which they are active. First we extract, for each rebel organization in a particular year, all locations that are recorded in UCDP-GED. This produces a yearly list of coordinates for each rebel organization, which we use to compute a convex hull (Eddy, 1977). The resulting polygons are projected on the earth's surface, providing us with the actual geographic area of the convex hulls. Figure 5 shows plots for the active areas of two Sudanese rebel organizations according to our measure, SPLM/A (left panel) and NDA (right panel), over time. We normalize the geographic area of each actor, by the sum of all actor areas in a country. Hence the geographic area of an actor can vary between zero and one.

We use our geographic measure of actor strength to calculate the power distribution within each potential tacit coalition, based on the Gini coefficient of power shares. The Gini coefficient is zero when all members of a potential coalition are active in similarly sized areas and one at the most unequal distribution of power.

We argue that the realization of a tacit coalition is not only dependent on the distribution of power within the coalition, but also the joint power of a coalition compared to other actors and coalitions. Hence, we sum the active areas of all actors in a potential coalition. This measure allows us to capture the overall coalition strength and identify tacit coalitions that have a greater chance 


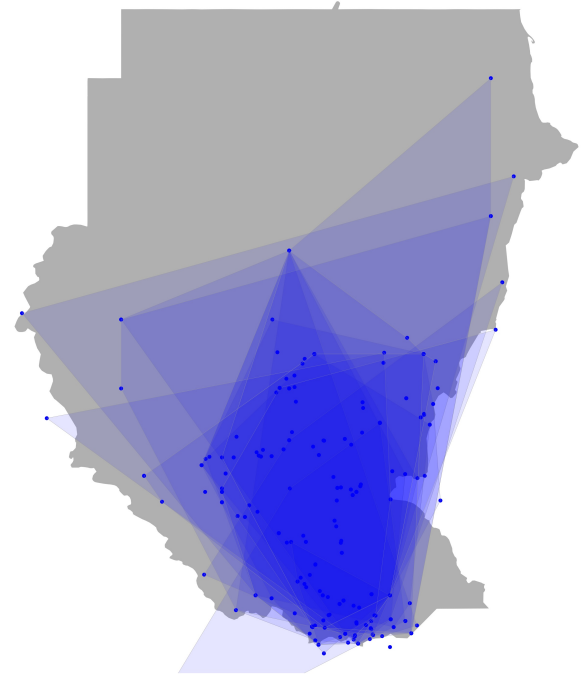

(A) SPLM/A

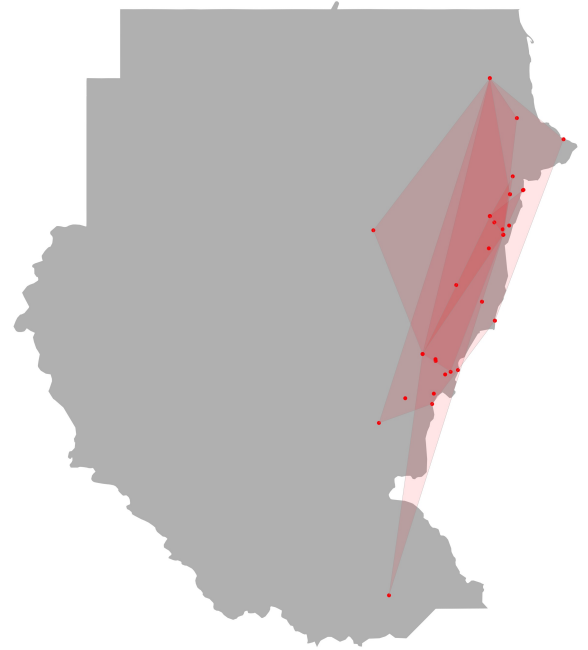

(B) NDA

FiguRE 5. Visualization of the rebel strength measure: Overlay of yearly active areas of the SPLM/A (left) and NDA (right) in Sudan. Points represent UCDPGED events, which provide the edges of the convex hull calculations.

of succeeding in a conflict. In line with Hypothesis 2, we expect that coalitions are less likely to form at very low or high joint capabilities.

Our theoretical model builds on the insight that coalition power is a function of synergies. We highlight two important sources of synergies. First, geographic distance which can allow coalition members to engage the opposition from different sides and second, different ethnic bases which impacts the ability to recruit and gain support from a greater share of the population.

We argue that geographic distance between rebel organizations in an important determinant of synergies, because rebel organizations that fight in different locations can engage the government on different fronts, forcing it to spread out its forces. In the context of international wars, it is widely accepted that states engaged on multiple fronts face a far greater challenge to succeed, and we transfer this notion to intra-state conflicts. However, there are not only benefits from fighting the opposition from different fronts. Greater distance between coalition partners can decrease the ability to coordinate and communicate. We believe that because conflict areas are comparatively small compared to international wars, the ability to engage the opposition at different locations outweighs the coordination costs. In line with this reasoning, we measure the average distance of the rebels' mean fighting locations within potential coalitions. We first calculate the mean fighting location for each rebel organization taking the mean longitude and latitude of all their fighting 
locations, resulting in a matrix $W$. We then calculate average distances between mean fighting locations for each $w_{i j}$.

As a second source of synergies we consider ethnicity and focus particularly on the role of identity for recruitment and support. Identity is important for recruitment in civil wars, because it allows organized groups to leverage existing cleavages for mobilization. This mobilization is thought to be particular successful if ethnic identities intersect with existing grievances (Wucherpfennig et al., 2012). In addition, ethnic identities also allow the identification of potential supporters, which facilitates recruitment of fighters. We argue that synergies between rebel organizations are greater if they are able to recruit from different ethnic groups and gain their support. Hence, similar to geographic distance, ethnic linkages may provide operational military advantages. This implies that coalitions that recruit or have support from different ethnic groups are more likely to realize synergies and should therefore be more likely to form tacit coalitions. This argument is different from (Gade et al. 2019) who stress coordination advantages of common identities and also (Christia, 2012 ) who largely discounts the role of identity in coalition formation.

We leverage information from the Actor Conflict Data to Ethnic Power Relations dataset (ACD2EPR Version 2014) (Wucherpfennig et al., 2012; Vogt et al., 2015) to identify which rebel organizations recruited or fought on behalf of the same ethnic groups. We aggregate this information to the coalition level and calculate the relative density of ethnic linkages in a coalition compared to the country level density, which is the potential grand coalition. This measure is formulated as:

$$
\frac{l_{g}}{|g|^{2}-|g|} / \frac{l_{n}}{n^{2}-n}
$$

where $|g|$ is the number of actors in a potential coalition and $n$ includes all actors in a country. The number of linkages in the potential coalition $\left(l_{g}\right)$ and on the country level $l_{n}$ are then divided by the number of possible linkages $\left(|g|^{2}-|g|\right.$ and $|n|^{2}-|n|$, respectively).

\subsection{Control variables}

We also include a number of control variables whose exclusion could potentially lead to omitted variable bias. First, we include the coalition size as the number of coalition members could impact the probability of being realized and be more unequal in size at the same time. Second, we control for infighting between potential coalition members (number of fighting events in coalition) as fighting among rebels is likely to affect coalition realization and could be driven by power relations among 
TABle 2. Estimates for the k-adic negative binomial models. Unit of analysis is a potential coalition-year. Outcome variables are the months a potential coalition is realized as a tacit coalition in a given year. Models include country-years with at least three actors (including the government).

\begin{tabular}{|c|c|c|c|c|c|}
\hline & Base Model & DV-lag Model & Main Model & $\mathrm{RE}$ & Sq Model \\
\hline \multirow[t]{2}{*}{ Intercept } & $3.92^{* * *}$ & $3.19^{* * *}$ & $2.82^{* * *}$ & $2.82^{* * *}$ & $2.79^{* * *}$ \\
\hline & $(0.23)$ & $(0.23)$ & $(0.25)$ & $(0.27)$ & $(0.25)$ \\
\hline \multirow[t]{2}{*}{ Coalition Gini } & $-1.47^{* * *}$ & $-1.40^{* * *}$ & $-1.35^{* * *}$ & $-1.57^{* * *}$ & $-1.42^{* * *}$ \\
\hline & $(0.33)$ & $(0.32)$ & $(0.32)$ & $(0.34)$ & $(0.32)$ \\
\hline \multirow[t]{2}{*}{ Proportion of Area Active } & -0.11 & -0.04 & $1.93^{* * *}$ & $2.19^{* * *}$ & $2.12^{* * *}$ \\
\hline & $(0.20)$ & $(0.19)$ & $(0.58)$ & $(0.65)$ & $(0.60)$ \\
\hline \multirow[t]{2}{*}{ Average Distance in Coalition $_{i n 1000}$} & $0.34^{* * *}$ & $0.29^{* *}$ & $0.40^{* * *}$ & $0.46^{* * *}$ & $0.69^{* *}$ \\
\hline & $(0.10)$ & $(0.10)$ & $(0.10)$ & $(0.11)$ & $(0.25)$ \\
\hline \multirow[t]{2}{*}{ Ethnic Linkage } & $-0.14^{* * *}$ & $-0.13^{* * *}$ & $-0.12^{* *}$ & $-0.11^{* *}$ & $-0.11^{* *}$ \\
\hline & $(0.04)$ & $(0.04)$ & $(0.04)$ & $(0.04)$ & $(0.04)$ \\
\hline \multirow[t]{2}{*}{ Coalition Size } & $0.29^{* * *}$ & $0.30^{* * *}$ & $0.30^{* * *}$ & $0.33^{* * *}$ & $0.28^{* * *}$ \\
\hline & $(0.07)$ & $(0.07)$ & $(0.07)$ & $(0.07)$ & $(0.07)$ \\
\hline \multirow[t]{2}{*}{ Infighting } & $0.05^{* * *}$ & $0.04^{* * *}$ & $0.05^{* * *}$ & $0.04^{* * *}$ & $0.05^{* * *}$ \\
\hline & $(0.01)$ & $(0.01)$ & $(0.01)$ & $(0.01)$ & $(0.01)$ \\
\hline \multirow[t]{2}{*}{ Government Coalition } & $-3.84^{* * *}$ & $-3.47^{* * *}$ & $-3.35^{* * *}$ & $-3.33^{* * *}$ & $-3.35^{* * *}$ \\
\hline & $(0.20)$ & $(0.20)$ & $(0.20)$ & $(0.20)$ & $(0.20)$ \\
\hline \multirow{2}{*}{ Possible Coalitions } & $-0.87^{* * *}$ & $-0.78^{* * *}$ & $-0.77^{* * *}$ & $-0.78^{* * *}$ & $-0.77^{* * *}$ \\
\hline & $(0.05)$ & $(0.04)$ & $(0.04)$ & $(0.05)$ & $(0.04)$ \\
\hline \multirow[t]{2}{*}{ Dependent Lag } & & $0.24^{* * *}$ & $0.23^{* * *}$ & $0.24^{* * *}$ & $0.23^{* * *}$ \\
\hline & & $(0.03)$ & $(0.03)$ & $(0.03)$ & $(0.03)$ \\
\hline \multirow[t]{2}{*}{ Sq. Proportion of Area Active } & & & $-2.05^{* * *}$ & $-2.38^{* * *}$ & $-2.19^{* * *}$ \\
\hline & & & $(0.58)$ & $(0.63)$ & $(0.60)$ \\
\hline \multirow[t]{2}{*}{ Sq. Average Distance in Coalition } & & & & & -0.08 \\
\hline & & & & & $(0.07)$ \\
\hline AIC & 3654.25 & 3592.27 & 3581.98 & 3575.32 & 3582.41 \\
\hline $\mathrm{BIC}$ & 3720.29 & 3664.92 & 3661.23 & 3661.17 & 3668.27 \\
\hline Log Likelihood & -1817.12 & -1785.14 & -1778.99 & -1774.66 & -1778.21 \\
\hline Num. obs. & 5454 & 5454 & 5454 & 5454 & 5454 \\
\hline
\end{tabular}

actors (Bakke, Cunningham and Seymour, 2012). Third, we code whether a potential coalition includes the government as this is likely to decrease the probability of coalition formation and correlate with power distribution with the potential coalition. Forth, we include a lagged measure of our main outcome variable to account for autocorrelation over time. Finally, we control for the number of potential coalitions as this is likely to affect the baseline probability that a specific coalition can be realized.

\section{K-ADic Negative Binomial Results}

Table 2 summarizes results from the k-adic negative binomial analysis. The k-adic approach is especially useful to shed light on the internal composition of coalitions. Hypothesis 1 states that realized tacit coalitions likely consist of partners of similar strength, Hypothesis 2 proposes that potential coalitions with very low and high joint capabilities are unlikely to form, and Hypothesis 
3 predicts that rebel organizations with greater synergies are more likely to form coalitions. We first provide a baseline model that does not account for any temporal dynamics (Base Model) and the second model (DV-lag Model) includes a lagged dependent variable. The third model (main model) includes the squared term of the potential coalitions' proportion of area active, while the forth model (RE Model) includes country random effects. We also estimate a separate version of the main model that features the squared average fighting distance in potential coalitions, assessing potential non-linear effects of this variable.

We begin the discussion of our results by focusing on the effect of the internal balance of power on the realization of tacit coalitions (Hypothesis 1). Across all models in Table 2, the estimated effect of the Coalition Gini coefficient is negative and significant at conventional levels, implying that unbalanced coalitions are less likely to be realized. The most conservative estimates for the coalition Gini are derived from the third model in Table 2. We will refer to this as our main model in the discussion. Estimating the same model specification with random effects on the country level provides similar estimates. In order to obtain a substantive interpretation of the estimated effects, we plot the predicted number of tacit coalition months per year at different levels of the Coalition Gini coefficient (Figure 6) holding all other variables at their mean values. The predictions are based on our main model for a rebel organization coalition (no government actor included) that has been realized for two months in the past year. Based on the model estimates, we demonstrate, e.g., that moving from a relative unbalanced $(\mathrm{Gini}=0.5)$ to a very balanced coalition $(\mathrm{Gini}=0)$ increases the number of months per year in a tacit coalition by about 0.5 months on average. Thus, the left panel in Figure 6 provides support to Hypothesis 1 that potential coalitions with decreasing power balances are less likely to be realized. The right panel shows the empirical distribution of the Gini coalition coefficient in the data. Since our results are robust to a DV-lag and random effects specification on the potential coalition level, we conclude that we have strong support for Hypothesis 1.

Hypothesis 2 implies that potential coalitions are less likely to be realized at low joint and very high joint capabilities. We measure joint capability as the sum of individual capacity within the coalition over the sum of all individual capacity. Individual capacity is measured by the convex hull around all events of an actor within a year. The main model and the random effect model in Table 2 tests the direct implication of Hypothesis 2. The estimated effect is as expected non-linear with an inverse-U shaped pattern. Hence, the main model in Table 2 demonstrates that greater 


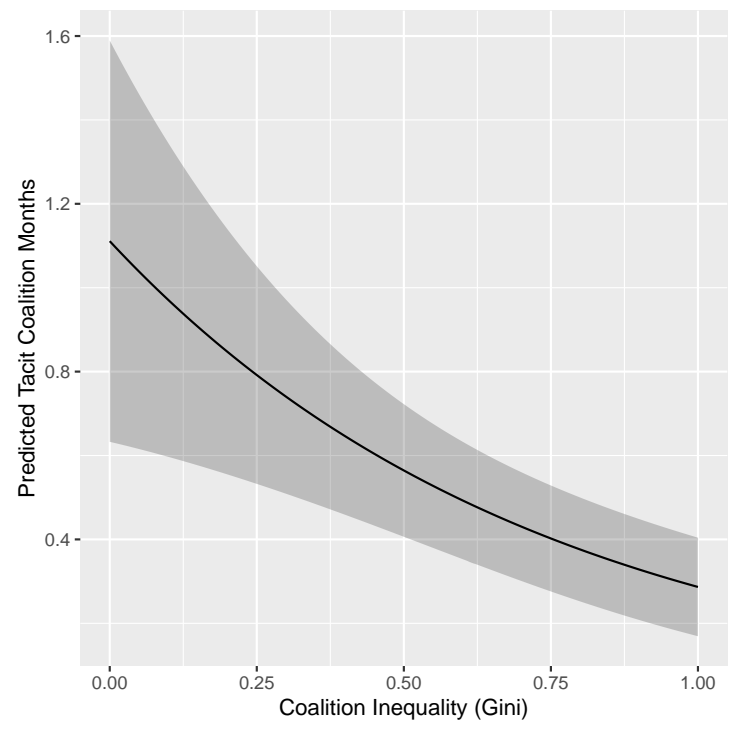

(A) Effect

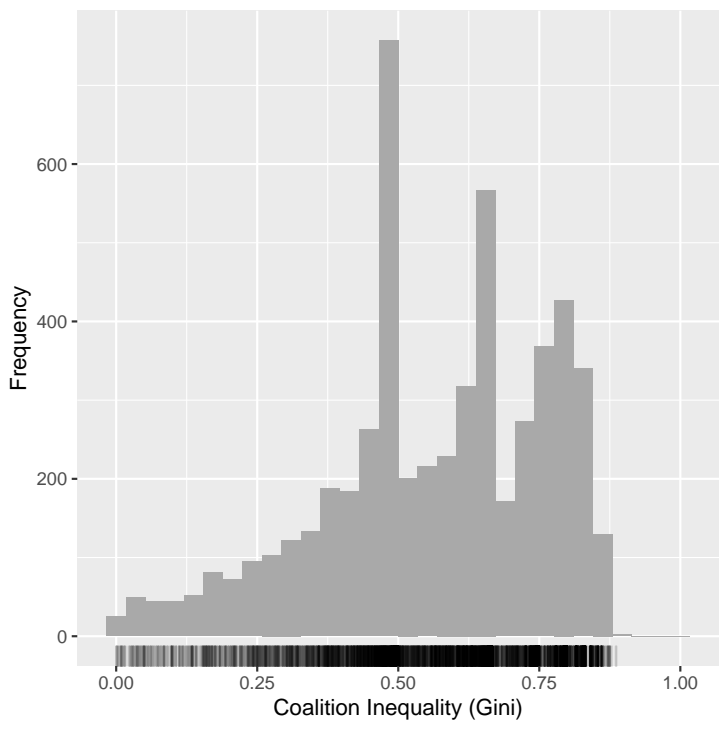

(B) Distribution

FiguRE 6. Left panel: Effect of the coalition Gini (coalition power distribution) on tacit coalition behavior with $95 \%$ confidence band. Right panel: Histogram of the empirical coalition Gini distribution.

joint active areas initially increase the probability of coalition realization, but that larger values are associated with a decrease in realization probability. This pattern is in line with the left panel of figure 2, which informed hypothesis 2. Interestingly, as discussed further below, the estimated effect for the main model plotted in the left panel of figure 7, also almost exactly replicates the additional simulations in theoretical figure 3 .

We next turn to the role of synergies and test the empirical implication of Hypothesis 3 that coalitions with higher synergies are more likely to be realized. We conceptualize synergies through the ability to form a heterogenous ethnic recruitment base (low ethnic linkage density in coalition) and the ability to engage the opposition from different geographic locations (higher geographic distance in coalition). In regard to ethnic synergies, Table 2 provides support for our argument that rebel organizations that recruit from different ethnic groups are more likely to generate synergies and therefore are more likely to form tacit coalitions. The estimated negative effect implies that coalitions with similar ethnic recruitment patterns are less likely being realized. In Figure 7 the effect of a coalitions' active area (Hypothesis 2) is plotted conditional on different degrees of ethnic linkage density. As ethnic linkage density increases, the lower the probability that a potential coalition will be realized (Hypothesis 3). 
Our second measure of synergies is the average fighting distance between rebel groups. We argued that actors which are able to attack the enemy from different geographic positions should enjoy greater synergies and therefore be more likely to form tacit coalitions. The results in Table 2 provide empirical support that a larger average fighting distance increases the instances of tacit coalition behavior. In the left panel of Figure 7, we replicate the theoretically derived Figure 3 based on our main model ${ }^{19}$ As the geographic distance within a potential coalition increases, the greater is its realization probability. In figure 7 the effect of a coalitions' active area (Hypothesis 2) is plotted conditional on different average distances in a coalition (in $\mathrm{km}$ ). The greater the average distance in a potential coalition, the more likely a coalition will be realized (Hypothesis 3).

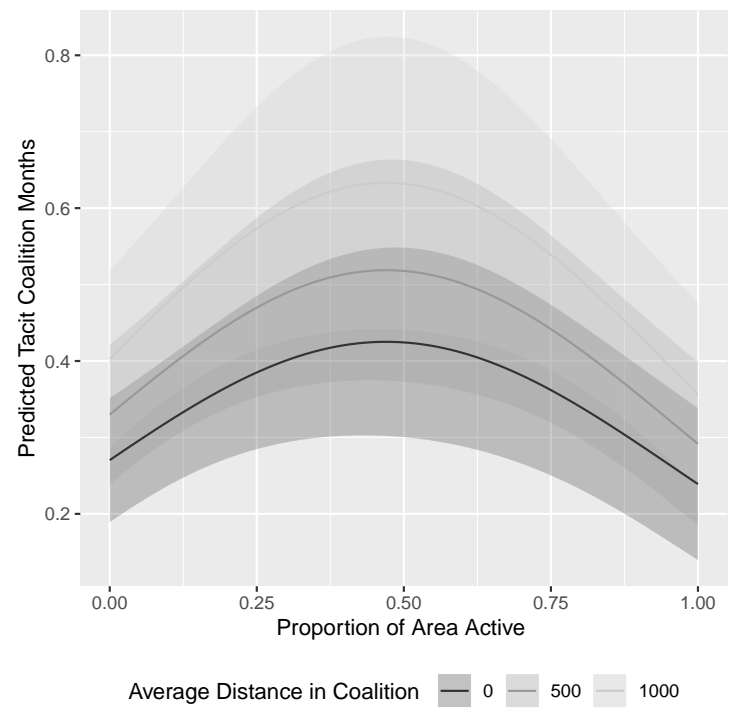

(A) Distance

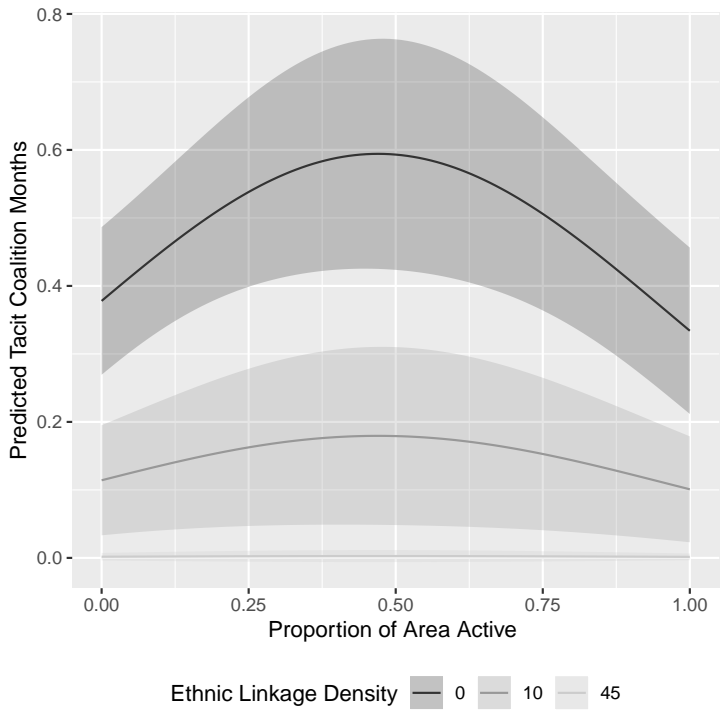

(B) Ethnic

FigURE 7. Effect of the geographic area a potential coalition is active in on the probability of coalition realization. Left panel plots the effect at different average distances in the coalition. Right panel plots the effect at different levels of ethnic linkage density. Effects on tacit coalition realization with $95 \%$ confidence band.

Turning to control variables, there are a number of interesting patterns. First, coalition size (cardinality) is positively associated with the realization of rebel coalitions. Coalitions with fewer members are less likely to form than larger tacit coalitions. Second, we find evidence that tacit coalition members display some infighting, but these effects are relatively small. Third, potential coalitions that include the government are less likely to form. This is not surprising as the majority

\footnotetext{
${ }^{19}$ Figure 3 maps an actor's individual capabilities into the share of equilibrium coalitions, not joint capabilities. However, since realized coalitions are more likely to be formed between equal size actors, the resulting predicted relationship is very similar.
} 
TABLE 3. Estimates for the k-adic negative binomial models. Unit of analysis is a potential coalition-year. Outcome variables are the months a potential coalition is realized as a tacit coalition in a given year. Models include country-years with at least three, four, five, and six actors (including the government).

\begin{tabular}{lcccc}
\hline & Base Model & GEqual 4 & GEqual 5 & GEqual 6 \\
\hline Intercept & $2.82^{* * *}$ & $2.47^{* * *}$ & $3.04^{* * *}$ & $2.99^{* * *}$ \\
& $(0.25)$ & $(0.31)$ & $(0.46)$ & $(0.79)$ \\
Coalition Gini & $-1.35^{* * *}$ & $-1.51^{* * *}$ & $-1.80^{* * *}$ & $-2.17^{* *}$ \\
& $(0.32)$ & $(0.38)$ & $(0.50)$ & $(0.70)$ \\
Proportion of Area Active & $1.93^{* * *}$ & $2.66^{* * *}$ & $2.55^{* *}$ & $4.10^{* *}$ \\
& $(0.58)$ & $(0.68)$ & $(0.87)$ & $(1.35)$ \\
Average Distance in Coalition ${ }_{i n 1000}$ & $0.40^{* * *}$ & $0.37^{* *}$ & $0.43^{* *}$ & $0.48^{*}$ \\
& $(0.10)$ & $(0.11)$ & $(0.15)$ & $(0.22)$ \\
Ethnic Linkage & $-0.12^{* *}$ & $-0.14^{* * *}$ & $-0.16^{* *}$ & $-0.15^{\circ}$ \\
& $(0.04)$ & $(0.04)$ & $(0.06)$ & $(0.08)$ \\
Coalition Size & $0.30^{* * *}$ & $0.34^{* * *}$ & $0.39^{* * *}$ & $0.45^{* * *}$ \\
& $(0.07)$ & $(0.08)$ & $(0.09)$ & $(0.11)$ \\
Infighting & $0.05^{* * *}$ & $0.03^{*}$ & 0.00 & 0.01 \\
& $(0.01)$ & $(0.01)$ & $(0.02)$ & $(0.02)$ \\
Government Coalition & $-3.35^{* * *}$ & $-3.33^{* * *}$ & $-2.66^{* * *}$ & $-3.12^{* * *}$ \\
& $(0.20)$ & $(0.27)$ & $(0.34)$ & $(0.59)$ \\
Possible Coalitions & $-0.77^{* * *}$ & $-0.73^{* * *}$ & $-0.81^{* * *}$ & $-0.83^{* * *}$ \\
& $(0.04)$ & $(0.05)$ & $(0.07)$ & $(0.11)$ \\
Dependent Lag & $0.23^{* * *}$ & $0.30^{* * *}$ & $0.32^{* * *}$ & $0.37^{*}$ \\
& $(0.03)$ & $(0.05)$ & $(0.07)$ & $(0.15)$ \\
Sq. Proportion of Area Active & $-2.05^{* * *}$ & $-2.64^{* * *}$ & $-2.59^{* *}$ & $-4.27^{* *}$ \\
& $(0.58)$ & $(0.71)$ & $(0.93)$ & $(1.60)$ \\
\hline AIC & 3581.98 & 2756.39 & 1894.28 & 1175.11 \\
BIC & 3661.23 & 2834.67 & 1970.90 & 1249.82 \\
Log Likelihood & -1778.99 & -1366.19 & -935.14 & -575.56 \\
Num. obs. & 5454 & 5030 & 4379 & 3734 \\
\hline$* * * p<0.001,{ }^{* *} p<0.01,{ }^{*} p<0.05,{ }^{\circ} p<0.1$ & & & & \\
& & & &
\end{tabular}

of rebel organizations have the goal to confront the government, even though instances of side switching are possible (Otto, 2018). Finally, the results demonstrate that coalitions that have been realized in the past year are likely to be realized again, and that environments with a larger number of possible coalitions decrease the probability of any one coalition being realized. This latter effect is driven by the logic of $\mathrm{k}$-adic research design. The year-on-year persistence of tacit coalitions provides assurance that our coalition measure is picking up a structurally important phenomenon.

We now assess the predictive performance of our k-adic negative binomial models. Figure 8 presents barplots to assess the predictive insample performance of the Main DV-lag Model (left panel) and Random Effects Model (right panel). Both models slightly under-predict the number of months potential coalitions are realized for lower values and slightly over-predicts for higher values. Overall, when considering the Root Squared Mean Error (RSME), the DV-lag Model (RMSE=1.19) is slightly outperforming the RE Model (RMSE $=1.22)$. 


\subsection{Robustness}

We assume that the empirical implications from our theoretical model are independent of the number of potential coalitions. In our main model we consider potential coalitions in country years with at least three actors (one government and at least two rebel organizations), but coalition dynamics might be different for larger sets of potential coalition members. Hence, we estimate our main model specification with country years that have at least four, five, and six actors. Table 3 demonstrates that our main results are robust to these different sample selection strategies. Only the precision of the ethnic linkage variables slightly decreases, while all other results remain unchanged.

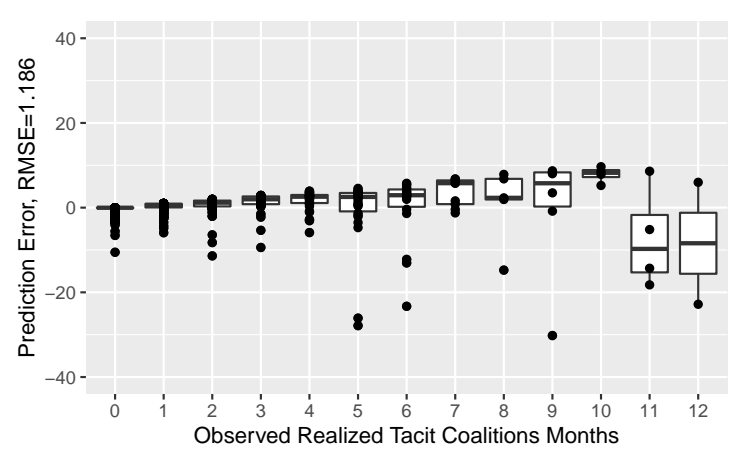

(A) DV-lag model

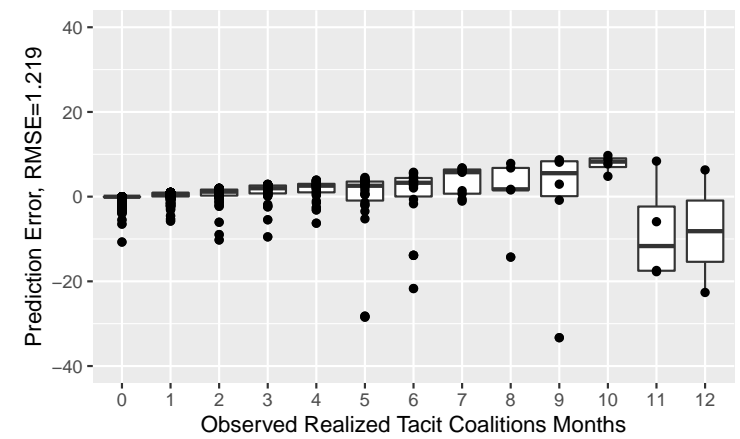

(B) RE-model

FiguRE 8. Left panel provides the prediction error of the DV-lag model for the observed realized coalition months. Right panel provides the prediction error for the random effect model.

\section{Conclusion}

Formal civil war coalitions are rare and we therefore focus on the explanation of tacit coalition behavior. Tacit coalitions are based on observable fighting activity and thus allow us to draw conclusions about when and how actors join or fight other warring parties. Our theoretical approach makes a number of important contributions, which are driven by our focus on military synergies between actors. This means that actors not only pool resources, but that they strategically enter coalitions that can unlock synergies to defeat the opposition. Overall, we make three important theoretical contributions. First, we show that for powerful actors, the marginal benefit from realizing synergies with an additional coalition partner declines. Because of this, very powerful actors will not join coalitions if there is any degree of commitment to sharing the spoils of victory in a way that deviates from the balance of power within the coalition. Thus, stronger actors are unwilling 
to join with weaker actors. Second, we demonstrate that this decreasing willingness of powerful groups to join coalitions and a lack of viable coalitions partners for less powerful groups explains balancing in coalitions. Third, our theory illustrates conditions under which powerful groups (for example government actors) nonetheless align with smaller rebel organizations to form supersized coalitions.

Empirically, we find strong evidence that rebel organizations of similar strength are more likely to join tacit coalitions. Powerful rebel groups are more likely to fight alone, while evenly matched groups tend to join forces. At the same time, smaller rebel groups are less likely to engage in coalition behavior. These patterns suggest that balancing dynamics play an important role within tacit coalitions. We also find that the overall distribution of power in a conflict is an important driver of tacit coalition behavior. Relatively small and especially large coalitions are less likely being realized. Finally, we demonstrate that pairs with higher synergies in a conflict are more likely to form coalitions. Taken together, these results are in line with our theoretical expectations and generate important new insights about the internal makeup of coalitions in civil war.

More broadly, our research contributes to the growing network analytic approach to the study of civil war. While we uncover some of the empirical variation in coalition behavior, our empirical analysis also shows that there remains a large amount of unmodeled variation in coalition formation. This implies that future research has much potential to further add to the explanation of coalition formation and breakup. This pertains especially to the conclusion of international actors, whose role has not been included in this research. This also indicates that we are still at the very beginning of understanding one of the most persistent and pertinent features of armed civil conflict. We very much believe that in addressing these important processes, researchers need to use theories and empirical approaches that take strategic incentives and the networked environment of armed groups seriously.

\section{REFERENCES}

Acemoglu, Daron, Georgy Egorov and Konstantin Sonin. 2008. "Coalition formation in nondemocracies." The Review of Economic Studies 75(4):987-1009.

Akcinaroglu, Seden. 2012. "Rebel Interdependencies and Civil War Outcomes." Journal of Conflict Revolution 56(5):879-903. 
Bakke, Kristin M., Kathleen Gallagher Cunningham and Lee J. M. Seymour. 2012. "A Plague of Initials: Fragmentation, Cohesion, and Infighting in Civil Wars." Perspectives on Politics 10(02):265-283.

Bapat, Navin A. and Kanisha D. Bond. 2012. "Alliances between Militant Groups." British Journal of Political Science 42(04):793-824.

Beardsley, Kyle, Kristian Skrede Gleditsch and Nigel Lo. 2015. "Roving Bandits? The Geographical Evolution of African Armed Conflicts." International Studies Quarterly 59(3):503-516.

Bloch, Francis. 1997. Non-cooperative models of coalition formation in games with spillovers. In New directions in the economic theory of the environment, ed. Carlo Carraro and Domenico Siniscalco. Cambridge Univ Pr pp. 311-352.

Bloom, Mia M. 2004. "Palestinian suicide bombing: Public support, market share, and outbidding." Political Science Quarterly 119(1):61-88.

Bormann, Nils-Christian. 2019. "Uncertainty, Cleavages, and Ethnic Coalitions." Journal of Politics 81(2):471-486.

Boulding, Kenneth E. 1962. "Conflict and Defense: A General Theory.".

Buhaug, Halvard, Lars-Erik Cederman and Jan Ketil Rød. 2008. "Disaggregating ethno-nationalist civil wars: A dyadic test of exclusion theory." International Organization 62(3):531-551.

Christia, Fotini. 2012. Alliance Formation in Civil War. Cambridge: Cambridge University Press. Conrad, Justin and Kevin Greene. 2015. "Competition, differentiation, and the severity of terrorist attacks." The Journal of Politics 77(2):546-561.

Cunningham, David E., Kristian Skrede Gleditsch and Idean Salehyan. 2009. "It Takes Two: A Dyadic Analysis of Civil War Duration and Outcome." Journal of Conflict Resolution 53(4):570597.

Cunningham, Kathleen Gallagher. 2011. "Divide and Conquer or Divide and Concede: How Do States Respond to Internally Divided Separatists?" American Political Science Review 105(02):275-297.

Cunningham, Kathleen Gallagher, Kristin M. Bakke and Lee J. M. Seymour. 2012. "Shirts Today, Skins Tomorrow." Journal of Conflict Resolution 56(1):67-93.

Dixit, Avinash. 1987. "Strategic behavior in contests." The American Economic Review pp. 891898. 
Dorff, Cassy, Max Gallop and Shahryar Minhas. 2020. "Networks of Violence: Predicting Conflict in Nigeria." The Journal of Politics Forthcoming.

Driscoll, Jesse. 2012. "Commitment problems or bidding wars? Rebel fragmentation as peace building." Journal of Conflict Resolution 56(1):118-149.

Eddy, William F. 1977. "A new convex hull algorithm for planar sets." ACM Transactions on Mathematical Software (TOMS) 3(4):398-403.

Esteban, Joan and Debraj Ray. 1999. "Conflict and Distribution." Journal of Economic Theory $87(2): 379-415$.

Esteban, Joan and Debraj Ray. 2008. "Polarization, fractionalization and conflict." Journal of Peace Research 45(2):163-182.

Fordham, Benjamin and Paul Poast. 2016. "All alliances are multilateral: rethinking alliance formation." Journal of Conflict Resolution 60(5):840-865.

Francois, Patrick, Ilia Rainer and Francesco Trebbi. 2015. "How is power shared in Africa?" Econometrica 83(2):465-503.

Gade, Emily Kalah, Michael Gabbay, Mohammed M Hafez and Zane Kelly. 2019. "Networks of Cooperation: Rebel Alliances in Fragmented Civil Wars." Journal of Conflict Resolution .

Garfinkel, Michelle R and Stergios Skaperdas. 2007. Economics of conflict: An overview. Vol. 2 Elsevier pp. 649-709.

Gates, Scott. 2002. "Recruitment and allegiance: The microfoundations of rebellion." Journal of Conflict resolution 46(1):111-130.

Greig, J. Michael. 2015. "Rebels at the Gates: Civil War Battle Locations, Movement, and Openings for Diplomacy." International Studies Quarterly 59(4):680-693.

URL: http://dx.doi.org/10.1111/isqu.12130

Herrero, Maria José. 1985. N-player Bargaining and Involuntary Unemployment PhD thesis Ph.D. Dissertation, London: London University.

Hirshleifer, Jack. 1988. "The Analytics of Continuing Conflict." Synthese 76(2):201-233.

Hirshleifer, Jack. 1995. Theorizing about conflict. In Handbook of defense economics, ed. Keith Hartley and Todd Sandler. Elsevier pp. 165-189.

Krause, Peter. 2017. Rebel Power: Why National Movements Compete, Fight, and Win. Cornell Studies in Security Affairs Ithaca, NY: Cornell University Press. 
Lyall, Jason. 2010. "Are coethnics more effective counterinsurgents? Evidence from the second Chechen war." American Political Science Review 104(1):1-20.

McKelvey, Richard D., Andrew M. McLennan and Theodore L. Turocy. 2013. "Gambit: Software Tools for Game Theory, Version 13.1.1." http://www.gambit-project.org.

Metternich, Nils W., Cassy Dorff, Max Gallop, Simon Weschle and Michael D. Ward. 2013. "Antigovernment Networks in Civil Conflicts: How Network Structures Affect Conflictual Behavior." American Journal of Political Science 57(4):892-911.

Morey, Daniel S. 2016. "Military coalitions and the outcome of interstate wars." Foreign Policy Analysis 12(4):533-551.

Nemeth, Stephen. 2014. "The Effect of Competition on Terrorist Group Operations." Journal of Conflict Resolution 58(2):336-362.

Niou, Emerson and Guofu Tan. 2005. "External Threat and Collective Action." Economic Inquiry $43(3): 519-530$.

Niou, Emerson MS, Peter C Ordeshook and Gregory F Rose. 1989. The balance of power: Stability in international systems. Cambridge: Cambridge University Press.

Nygård, Håvard Mokleiv and Michael Weintraub. 2015. "Bargaining Between Rebel Groups and the Outside Option of Violence." Terrorism and Political Violence 27(3):557-580.

Organski, Abramo FK. 1958. World politics. Knopf.

Otto, Sabine. 2018. "The grass is always greener? Armed group side switching in civil wars." Journal of Conflict Resolution 62(7):1459-1488.

Phillips, Brian J. 2014. "Terrorist group cooperation and longevity." International Studies Quarterly $58(2): 336-347$.

Poast, Paul. 2010. "Multilateral Events." Political Analysis 18:403-425.

Popovic, Milos. 2018. "Inter-Rebel Alliances in the Shadow of Foreign Sponsors." International Interactions 44(4):749-776.

Prunier, Gérard. 2004. "Rebel movements and proxy warfare: Uganda, Sudan and the Congo (1986-99)." African Affairs 103(412):359-383.

Quinn, Jason, Madhav Joshi and Erik Melander. 2019. "One Dyadic Peace Leads to Another? Conflict Systems, Terminations, and Net Reduction in Fighting Groups.” International Studies Quarterly . 
Ray, Debraj. 2007. A Game-Theoretic Perspective on Coalition Formation. Oxford: Oxford University Press. Kindle file.

Riker, William H. 1962. The Theory of Political Coalitions. New Haven, CT: Yale University Press.

Sandler, Todd, Frederic P. Sterbenz and John Posnett. 1987. "Free riding and uncertainty." European Economic Review 31(8):1605 - 1617.

URL: http://www.sciencedirect.com/science/article/pii/S0014292187800296

Seymour, Lee JM, Kristin M Bakke and Kathleen Gallagher Cunningham. 2016. "E pluribus unum, ex uno plures: Competition, violence, and fragmentation in ethnopolitical movements." Journal of Peace Research 53(1):3-18.

Skaperdas, Stergios. 1998. "On the formation of alliances in conflict and contests." Public Choice 96(1-2):25-42.

Strachan, Hew. 2006. "Training, morale and modern war." Journal of Contemporary History $41(2): 211-227$.

Sundberg, Ralph and Erik Melander. 2013. "Introducing the UCDP Georeferenced Event Dataset." Journal of Peace Research 50(4):523-532.

Tan, Guofu and Ruqu Wang. 2010. "Coalition Formation in the Presence of Continuing Conflict." International Journal of Game Theory 39(1):273-299.

Vogt, Manuel, Nils-Christian Bormann, Seraina Rüegger, Lars-Erik Cederman, Philipp Hunziker and Luc Girardin. 2015. "Integrating Data on Ethnicity, Geography, and Conflict: The Ethnic Power Relations Data Set Family." Journal of Conflict Resolution 59(7):1327-1342.

Wagner, R Harrison. 1986. "The theory of games and the balance of power." World Politics $38(4): 546-576$.

Walter, Barbara F. 2019. "Explaining the number of rebel groups in civil wars." International Interactions 45(1):1-27.

Waltz, Kenneth N. 1964. "The stability of a bipolar world." Daedalus pp. 881-909.

Waltz, Kenneth N. 1979. Theory of International Politics. Reading: Addison-Wesley.

Weisiger, Alex. 2016. "Exiting the Coalition: When Do States Abandon Coalition Partners during War?" International Studies Quarterly 60(4):753-765.

Wolford, Scott. 2015. The politics of military coalitions. Cambridge University Press.

Wood, Reed M and Jacob D Kathman. 2015. "Competing for the Crown Inter-rebel Competition and Civilian Targeting in Civil War." Political Research Quarterly 68(1):167-179. 
Wucherpfennig, Julian, Nils W. Metternich, Lars-Erik Cederman and Kristian Skrede Gleditsch. 2012. "Ethnicity, the state, and the duration of civil war." World Politics 64(1):79-115.

Young, John. 2005. "Sudan: a flawed peace process leading to a flawed peace." Review of African political economy 32(103):99-113. 


\section{Appendix}

\subsection{Discussion of sharing rule}

The simulation analysis shows that when sharing according to relative power, any coalition is sustainable as a Nash equilibrium. This is a boundary case. Figure A1 illustrates that even a small degree of sharing of the spoils of victory means that some coalitions are no longer attractive enough for all members.

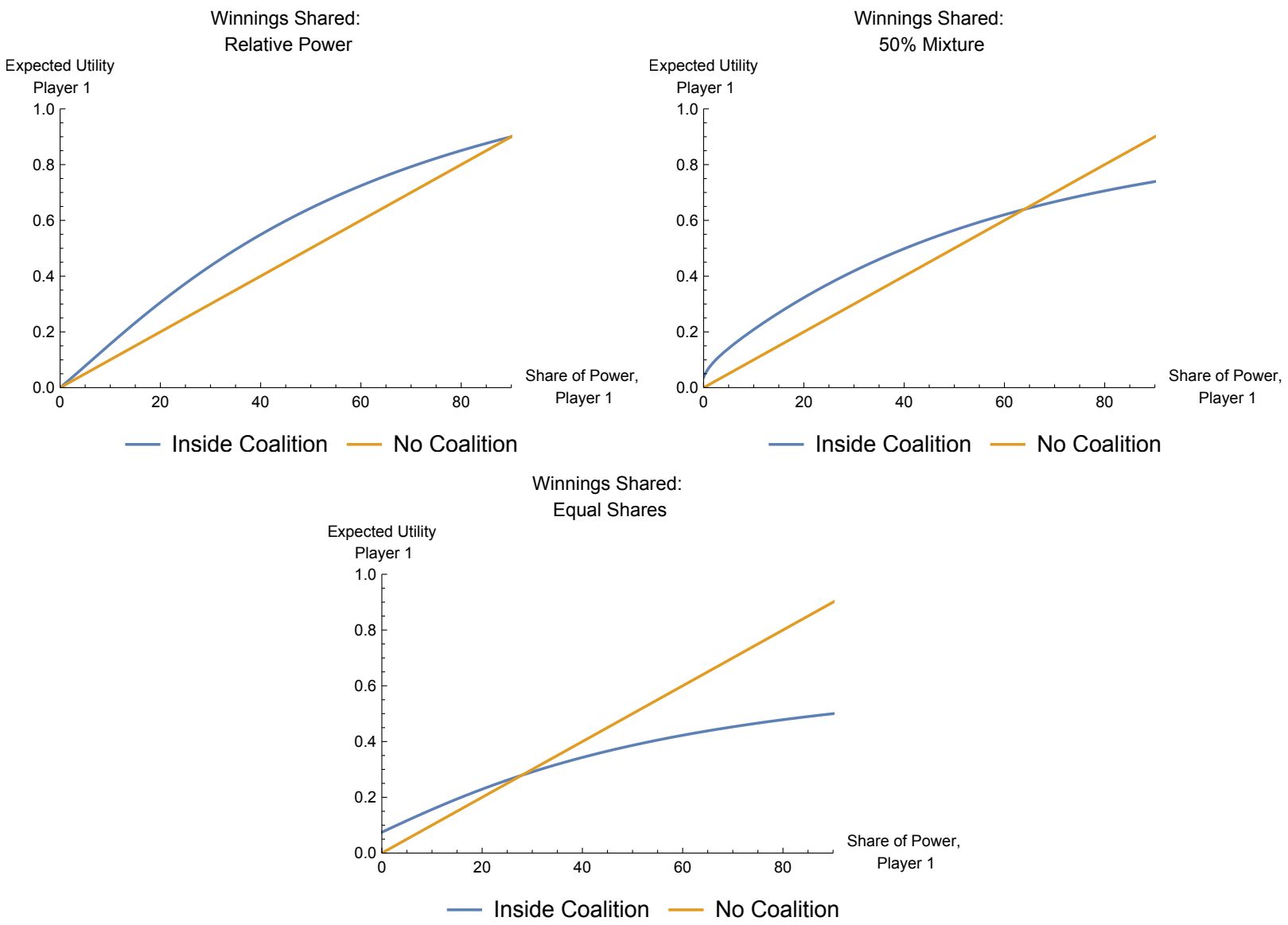

FigURE A1. Illustration of payoffs that player 1 can realize when forming a coalition with player 2, against player 3 . The power of 1 changes, while 2 is held constant at $10 \%$. The total number of players is $n=3$, and synergy is set to $\alpha=1.2$.

It shows the payoffs that player 1 can realize when forming a coalition with player 2 in opposing player 3 (blue line). The yellow line shows what 1 can receive when fighting alone. The comparison assumes that player 2 has a 10 percent power share and does not enter into coalition with player 3 . The first graph captures sharing according to relative power. Regardless of the relative power of player 1 , being in coalition with 2 always pays more than going it alone. The third graph depicts 
the other ideal type, with players 1 and 2 sharing the spoils from victory in equal parts. Now, joining a coalition only pays if player 1's power share is less than about 30 percent. The second graph illustrates how any shift towards greater sharing of spoils implies that the some coalitions become unattractive to player 1, as the blue curve dips below the yellow curve. The graph uses a mixed sharing rule that is based on a convex combination of the ideal types, with 50 percent weights.

The sensitivity of equilibrium outcomes to the sharing rule happens for two reasons. First, marginal gains in the coalition's aggregate probability of winning decline when total coalition strength surpasses 50 percent. This occurs because the coalition's joint force function is concave, inducing a concave shape into the conflict success function. Relatively powerful individual players are more likely to be part of a coalition that surpasses this threshold, and players with 50 percent or more of capabilities are always above this threshold. Second, sharing rules that deviate from the relative distribution of power among coalition members, even if only very slightly, transfers utility from larger to smaller actors. As the power difference between actors increases, so do these transfers. Eventually the size of the transfer outstrips the gains that were jointly realized from the pooling of capabilities.

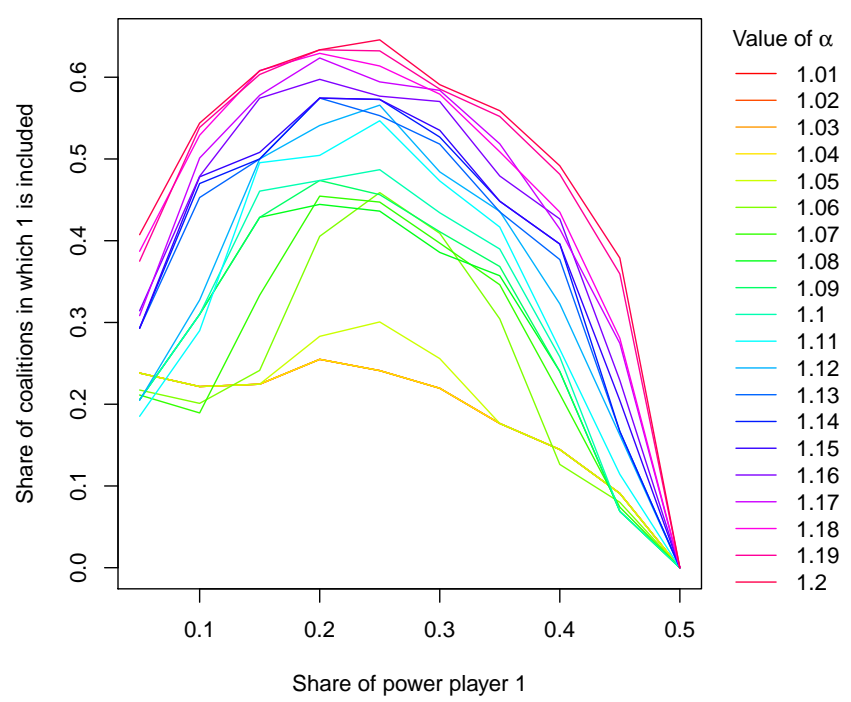

FiguRE A2. Illustration of how the relative power of an actor affects whether the actor forms part of a coalition. It shows the share of all feasible coalitions that include player 1 , as a function of player 1's relative power. The synergy parameter is varied according to $\alpha \in[1.01,1.2]$. 
The analysis presented in figure A1 has two important substantive takeaways. First, armed actors that have equal capabilities face no distributional challenges, regardless of commitment abilities and their absolute size, and therefore should be more likely to form coalitions. For exactly identical power shares in a coalition of two actors, actor utilities under the relative power and equal sharing rules become equal. Second, there is a natural upper bound for the relative capabilities of individual actors, above which it does not pay to enter into coalitions.

Figure A2 is obtained by taking the total number of feasible coalitions (i.e. those forming a Nash equilibrium) for a given distribution of capabilities and synergy parameter $\alpha$, and calculating the share of coalitions that include player number 1. This share is then mapped against player 1's relative power. The result shows a clear inverse U-shaped relationship between player's size and coalition activity. Both very powerful and very weak players are less likely to be part of a coalition. As expected, players that have 50 percent of capabilities or more never enter into coalitions. Note that these patterns become more pronounced as military synergy increases.

Given that actors of equal size should be most likely to join forces, how can we make sense of the relatively lack of coalition activity for smaller actors? The answer lies in the relative scarcity of small actors across all permutations of the power distribution. Very small actors would benefit from joining forces with equal sized or larger actors, but when holding the number of actors constants, being very small means a higher chance of having to deal with larger actors. These larger actors in turn are less willing to joing coalitions with small actors.20

\footnotetext{
${ }^{20}$ Figure $\mathrm{A} 3$ in the appendix illustrates this effect.
} 
Figure A3. Gini of power inequality in coalitions, median

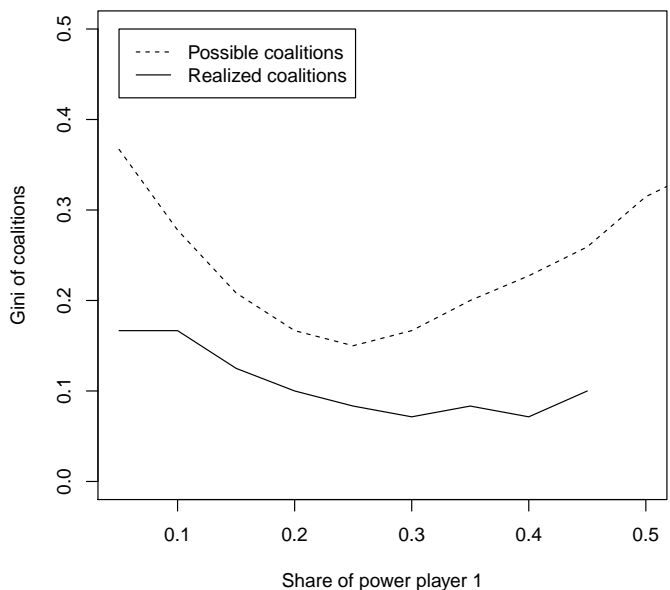

Figure A3 shows that less powerful actors systematically can't find coalition partners because of power asymmetries. The dashed line presents the median degree of inequality within all possible coalitions (measured as Gini coefficient) for a given size of player 1. Larger values stand for more inequality. The solid line shows the coefficient for those coalitions that are realized in equilibrium. The comparison shows two things. First realized coalitions tend to be more equally balanced than all possible coalitions throughout (i.e. the dashed line is above the solid line). Second, larger gaps are opening up for actors that have less than 15 percent or more than 30 percent of power resources. 
Martin C. Steinwand: Department of Government

Current address: University of Essex

Email address: m.steinwand@essex.ac.uk

Nils W. Metternich: Department of Political Science

Current address: University College London, London, WC1H 9QU, UK

Email address: n.metternich@ucl.ac.uk 